\title{
A survey on critical factors influencing new advertisement methods
}

\author{
Naser Azad $^{a^{*}}$, Seyed Fovad Zarifi ${ }^{\mathrm{b}}$, Somayeh Hozori ${ }^{\mathrm{b}}$ and Shahram Hashemi ${ }^{\mathrm{b}}$
}

${ }^{a}$ Department of Management, Islamic Azad University, South Tehran Branch, Tehran, Iran

${ }^{b}$ Master student, Department of Management, Islamic Azad University, South Tehran Branch, Tehran, Iran

\section{CHRON I C L E}

Article history:

Received October 25, 2012

Received in revised format

12 December 2012

Accepted 14 December 2012

Available online

December 142012

Keywords:

Food industry

Advertisement

Factor analysis

Soft drink

\begin{abstract}
A B S T R A C T
Soft drink beverages are important part of many people's foods and many prefer soft drink to water when they have dinner. Therefore, this business model can be considered as the longest lasting sector for many years and there has been not much change in these products. However, new methods of advertisement play important role for increasing market share. In this paper, we study the impact of new methods of advertisement in product development. The proposed study of this paper designs a questionnaire for one of Iranian soft drink producers, which consisted of 274 questions in Likert scale and uses factor analysis (FA) to analyze the results. The study selects 250 people who live in city of Tehran, Iran and Cronbach alpha has been calculated as 0.88 , which is well above the minimum desirable limit. According to our results, there were six important factors impacting in product development, including modern advertisement techniques, emotional impact, strategy of market leadership, pricing strategy, product life chain and supply entity. The most important factor loading in these six components include impact of social values, persuading unaware and uninformed customers, ability to monopolizing in production, improving pricing techniques, product life cycle and negative impact of high advertisement.
\end{abstract}

\section{Introduction}

Soft drink beverages are important part of many people's foods. Many people prefer soft drink to water when they have dinner. Therefore, this business model can be considered as the longest lasting sector for many years and there has been not much change in products. Advertisement plays an important role to exposure products and services in different industries. Advertisement in soft drink commodities is one of the most important ways to get into the market and business units. One primary question in this market is to learn more about the effects of various advertisement techniques especially the newly introduced ones such as social pages, email messages, etc. During the past few decades, there have been many studies associated with measuring the impact of advertisement in soft drink industry. 
Kioulafas (1985) studied the implementation of quantitative techniques in analyzing the Greek soft drink market. The paper developed single equation and simultaneous-equation regression models and compared the results with time-series data. The use of these techniques in a real life case brought out some problem of interelationships existing between advertising and sales of products with some small differences.

Probart et al. (2006) explained the extent and locations of soft drink advertisements on high school campuses in Pennsylvania and detected important factors associated with them. They used a threephase survey strategy including distribution of a postcard reminder 1 to 2 weeks after the initial survey distribution, and mailing of a second survey to nonrespondents 1 to 2 weeks after mailing of the postcard. There were 228 school foodservice directors (84\%) returned surveys and the data were analyzed using linear multiple regression analyses. The results recommended that commercialization and sales incentives might impact to contribute to school environments, which are not "nutritionfriendly.

Andreyeva et al. (2011) investigated the direct impact of food advertising on children's diet and dietrelated health, particularly in non-experimental settings. They investigated the relationship between exposure to food advertising on television and children's food consumption and body weight and recommended that soft drink and fast food television advertising was associated with increased consumption of soft drinks and fast food among elementary school children (Grade 5).

Grimm et al. (2004) investigated different factors associated with soft drink consumption in schoolaged children. They concluded that different factors could be associated with soft drink intake in school-aged children, soft drink consumption habits of parents and friends, most notably taste preferences, soft drink availability in the home and school, and television viewing. Tay (2005) in another survey studied the effectiveness of the anti-drink driving and anti-speeding enforcement and publicity campaigns used in the Australian State of Victoria. They reported that the anti-drink driving enforcement and publicity campaigns had a significant impact in reducing crashes but their interactive effect was anti-complementary.

Ramanathan and Muyldermans (2010) identified demand factors for promotional planning and forecasting in an empirical case study of a soft drink company in the UK. They used structural equation modeling for this purpose and the results confirmed the impact of the promotional factors in the sales uplift for all products. They also recommended various demand structures for different product families, and confirmed the relative importance of collecting and exchanging the proper supply chain information.

In this paper, we present an empirical survey to investigate the effects of new methods of advertisements on soft drink industry using factor analysis. During the past few years, factor analysis has been widely used to detect important factors influencing various businesses. Azad et al. (2013), for instance, determined critical components in agricultural insurance using factor analysis. Azad and Sadeghi (2012) performed an empirical study to determine effective factors on organizational commitment using factor analysis. Abdolvand et al. (2012) studied effective factors for the success of tourism industry in Iran using factor analysis. Azad et al. (2012) investigated critical success factors in industrial marketing supply chain management by implementing factor analysis. Mansouri Moayyed et al. (2012) studied the role of advertising through social networks to promote brand equity using factor analysis.

\section{The proposed study}

In this survey, we consider the impact of new methods of advertisement in product development. The proposed study of this paper designs a questionnaire for one of Iranian soft drink producers, which consists of 274 questions in Likert scale. We have used factor analysis (FA) to analyze the results and 
Cronbach alpha (Cronbach, 1951) has been calculated as 0.88 , which is well above the minimum desirable limit. Since FA is sensitive against Skewness coefficient, we have decided to remove questions 1, 2, 10, 13, 16, 19, 20 and 23 and out of 25 variables we have extracted 6 factors. KMO and Bartlett's Test yields Kaiser-Meyer-Olkin Measure of Sampling Adequacy as 0.623 and ChiSquare value is equal to 3599 with 300 degrees of freedom and the level of significance is equal to 0.000. The six influencing factors are modern advertisement techniques, emotional impact, strategy of market leadership, pricing strategy, product life chain and supply entity.

\section{The results}

In this section, we present details of six factor extracted from factor analysis.

\subsection{Modern advertisement techniques}

The first factor is associated with modern advertisement technique, which includes four variables: advertisement through email facilities, new media, detecting appropriate path for introducing products and the impact of social values. Chronbach alpha has been calculated as 0.649 and Table 1 summarizes the results.

\section{Table 1}

The results of factor analysis for modern advertisement technique

\begin{tabular}{lcccc}
\hline Factor & Factor weight & Eigenvalues & \% of variance & Accumulated \\
\hline Advertisement through email facilities & 0.840 & & & \\
New media & 0.869 & & & \\
Detecting appropriate path for introducing products & 0.541 & & & \\
Impact of social values & $\mathbf{0 . 8 8 4}$ & 1.976 & 49.407 & 49.407 \\
\hline
\end{tabular}

As we can observe from the results of Table 1, the last factor, the impact of social values, maintains the highest factor weight, 0.884 , followed by new media and advertisement through email facilities and it could explain $49.407 \%$ of variance.

\subsection{Emotional impact}

The second factor is associated with modern advertisement technique, which includes four variables: continuous advertisement, sale's growth, persuading potential customers and persuading unaware and uninformed customers. Chronbach alpha has been calculated as 0.578 and Table 2 demonstrates the results.

\section{Table 2}

The results of factor analysis for emotional impact

\begin{tabular}{lcccc}
\hline Factor & Factor weight & Eigenvalues & \% of variance & Accumulated \\
\hline Continuous advertisement & 0.653 & & & \\
Sale’s growth & 0.628 & & & \\
Persuading potential customers & 0.738 & & & \\
Persuading unaware and uninformed customers & $\mathbf{0 . 7 4 0}$ & 1.779 & 44.483 & 44.483 \\
\hline
\end{tabular}

As we can observe from the results of Table 2, the last factor, the impact of persuading unaware and uninformed customers maintains the highest factor weight, 0.740, followed by Persuading potential customers, continuous advertisement and sale's growth it could explain $44.483 \%$ of variance.

\subsection{Strategy of market leadership}

The third factor is associated with strategy of market leadership, which includes four variables: having a full market share when a new product is introduced, ability to monopolizing in production, 
existing competition among producers and dynamic advertisement during the introduction of a new product. Chronbach alpha has been calculated as 0.468 and Table 3 shows the results.

The results of Table 3 show that, the second factor, Ability to monopolizing in production keeps the highest factor weight, 0.760, followed by existing competition among producers, Dynamic advertisement during the introduction of a new product and having a full market share when a new product is introduced and it could explain $38.064 \%$ of variance.

\section{Table 3}

The results of factor analysis for strategy of market leadership

\begin{tabular}{lcccc}
\hline Factor & Factor weight & Eigenvalues & \% of variance & Accumulated \\
\hline $\begin{array}{l}\text { Having a full market share when a new product is } \\
\text { introduced }\end{array}$ & 0.586 & & & \\
Ability to monopolizing in production & $\mathbf{0 . 7 6 0}$ & 1.523 & 38.064 & 38.064 \\
Existing competition among producers & 0.679 & & \\
$\begin{array}{l}\text { Dynamic advertisement during the introduction of a } \\
\text { new product }\end{array}$ & 0.643 & & \\
\hline
\end{tabular}

\subsection{Pricing strategy}

The fifth factor is associated with pricing strategy, which includes three variables: improving pricing techniques, customer demands over time and pricing decisions. Chronbach alpha has been calculated as 0.447 and Table 5 presents the results.

\section{Table 5}

The results of factor analysis for pricing strategy

\begin{tabular}{lcccc}
\hline Factor & Factor weight & Eigenvalues & \% of variance & Accumulated \\
\hline Improving pricing techniques & $\mathbf{0 . 8 1 4}$ & 1.460 & 48.466 & 48.466 \\
Customer demands over time & 0.580 & & & \\
Pricing decisions & 0.677 & & & \\
\hline
\end{tabular}

The results of Table 5 explain that, the first factor, improving pricing techniques maintains the highest factor weight, 0.814 , followed by customer demands over time and pricing decisions and it could explain $48.466 \%$ of variance.

\subsection{Product life chain}

The fifth factor is associated with product life chain, which includes three variables: impacts of competitors, product life cycle and persuading customers. Chronbach alpha has been calculated as 0.518 and Table 5 presents the results.

\section{Table 5}

The results of factor analysis for product life chain

\begin{tabular}{|c|c|c|c|c|}
\hline Factor & Factor weight & Eigenvalues & $\%$ of variance & Accumulated \\
\hline Impacts of competitors & 0.573 & & & \\
\hline Product life cycle & 0.695 & 1.539 & 51.304 & 51.304 \\
\hline Persuading customers & 0.632 & & & \\
\hline
\end{tabular}

The results of Table 5 explain that, the second factor, product life cycle has the highest factor weight, 0.695 , followed by persuading customers and impacts of competitors and it could explain $51.304 \%$ of variance. 


\subsection{Supply entity}

The sixth factor is associated with supply entity, which includes three variables: impacts of competitors, product life cycle and persuading customers. Chronbach alpha has been calculated as 0.518 and Table 5 presents the results.

The results of Table 6 explain that, the third factor, negative impact of high advertisement has the highest factor weight, 0.655 , followed by brand identity and feedback for applying new strategies and it could explain $55.945 \%$ of variance.

\section{Table 5}

The results of factor analysis for product life chain

\begin{tabular}{lcccc}
\hline Factor & Factor weight & Eigenvalues & \% of variance & Accumulated \\
\hline Feedback for applying new strategies & 0.538 & & & \\
Brand identity & 0.598 & & & \\
Negative impact of high advertisement & $\mathbf{0 . 6 5 5}$ & 1.678 & 55.945 & 55.945 \\
\hline
\end{tabular}

\section{Conclusion}

In this paper, we have presented an empirical study to investigate the impact of new methods of advertisement in product development. The proposed study of this paper designed a questionnaire for one of Iranian soft drink producers, which consisted of 274 questions in Likert scale. We have used factor analysis (FA) to analyze the results and Cronbach alpha has been calculated as 0.88 . According to our results, there were six important factors impacting in product development, including modern advertisement techniques, emotional impact, strategy of market leadership, pricing strategy, product life chain and supply entity. The most important factor loading in these six components include impact of social values, persuading unaware and uninformed customers, ability to monopolizing in production, improving pricing techniques, product life cycle and negative impact of high advertisement.

\section{Acknowledgment}

We would like to thank the anonymous referees for constructive comment on earlier version of this paper.

\section{References}

Abdolvand, M.A., Heidarzadeh, K., \& Esfarjani, B. (2012). An empirical investigation on effective factors for the success of tourism industry in Iran. Management Science Letters, 2(7), 2493-2500.

Andreyeva, T., Kelly, I.R., \& Harris, J.L. (2011). Exposure to food advertising on television: Associations with children's fast food and soft drink consumption and obesity. Economics \& Human Biology, 9(3), 221-233.

Azad, N., Heidari Kord Zangeneh, G., Seyed Ali Akbar, S. M., \& Valipour, A. (2013). A survey on critical factors influencing agricultural insurance. Management Science Letters, 3(1), 237-242.

Azad, N., \& Sadeghi, S. (2012). An empirical study to determine effective factors on organizational commitment. Management Science Letters, 2(8), 2981-2986.

Azad, N., Seyed Aliakbar, S. M., Nayeri, A. (2012). Critical success factors in industrial marketing supply chain management. Management Science Letters, 2(7), 2667-2672.

Cronbach, L. J. (1951). Coefficient alpha and the internal structure of tests. Psychometrika, 16(3), 297-334.

Grimm, G.C., Harnack, L., \& Story, M.(2004). Factors associated with soft drink consumption in school-aged children. Journal of the American Dietetic Association, 104(8), 1244-1249 
Kioulafas, K.E. (1985). A quantitative analysis of the Greek soft-drink market, or: How your advertisement will help your competitor's sales. European Journal of Operational Research, 21(2), 165-171.

Mansouri Moayyed, F., Dehyadegari, S., \& Bakhshizadeh, A. (2012). The role of advertising through social networks to promote brand equity. Management Science Letters, 2(6), 1907-1912.

Probart, C., McDonnell, E., Bailey-Davis, L., \& Weirich, J.E. (2006). Existence and Predictors of Soft Drink Advertisements in Pennsylvania High Schools. Journal of the American Dietetic Association, 106(12), 2052-205.

Ramanathan, U., \& Muyldermans, L. (2010). Identifying demand factors for promotional planning and forecasting: A case of a soft drink company in the UK. International Journal of Production Economics, 128(2), 538-545.

Tay, R. (2005). The effectiveness of enforcement and publicity campaigns on serious crashes involving young male drivers: Are drink driving and speeding similar? Accident Analysis \& Prevention, 37(5), 922-929. 